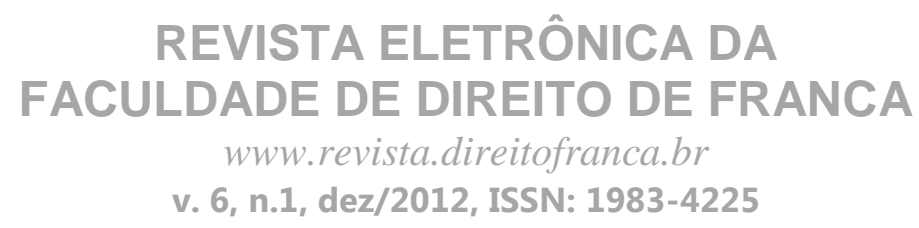

\title{
CULPABILIDADE, LIVRE-ARBÍTRIO E RESPONSABILIDADE JURÍDICA: NOTAS SOBRE O PENSAMENTO JUSFILOSÓFICO DE HANS WELZEL
}

Daniela Rezende Oliveira

http://buscatextual.cnpq.br/buscatextual/visualizacv.do?id=K4242673Y1

\begin{abstract}
Resumo: Para Hans Welzel, toda ação humana, em regra, possui finalidade que se encerra no momento da tomada da decisão de vontade da ação, sendo que todo comportamento humano livre e consciente tem uma estrutura finalística porque dirigido por uma vontade. Segundo Hans Welzel, o objeto de interesse do Direito Penal é, justamente, a finalidade e intencionalidade de uma ação humana. Entendendo-se que o principal ponto de interesse da dogmática jurídico-penal é o comportamento humano que pode ser dirigido pela vontade de ação, o exame acerca do problema do livre-arbítrio é necessário, tendo em vista ser ele o ponto de partida e o fundamento da culpabilidade - e, via de consequência, da imputabilidade e da responsabilidade jurídica. $\mathrm{O}$ presente artigo tem como objetivo demonstrar a estreita relação entre culpabilidade, livre-arbítrio, responsabilidade jurídica e a legitimidade do direito para punir no pensamento jusfilosófico de Hans Welzel. Além disso, o texto revela a estreita relação entre o direito e a moral na doutrina deste jusfilósofo, bem como, a necessidade de o Direito proteger e assegurar os valores éticosociais mais importantes para a sociedade.
\end{abstract}

Palavras-chave: livre-arbítrio - capacidade de culpabilidade - culpabilidade - responsabilidade jurídica.

\section{Culpability, Free-Will and Legal Responsability: notes about the legal-philosophical thought of Hans Welzel}

\begin{abstract}
For Hans Welzel, all human action, as a rule, has a purpose which terminates at the time of making the decision of will of action, and that all free and conscious human behavior has a finalistic structure because it is directed by a will.

According to Hans Welzel, the criminal law's object of interest is precisely the purpose and intentionality of human action. Understanding that the main point of interest of the legal criminal dogmatic is the human behavior that can be driven by the will of action, the examination of the free will's problem is necessary considering that he is the starting point and foundation of culpability - and, as a consequence, the liability and legal responsibility. This article aims to demonstrate the close relationship between culpability, free will, legal responsibility and legitimacy of the right to punish in the legal-philosophical thought of Hans Welzel. Moreover, the text reveals the close relationship between law and morality in this legal-philosophical doctrine, as well as the need to protect and ensure the ethical and social values that are more important to society.
\end{abstract}




\section{REVISTA ELETRÔNICA DA \\ FACULDADE DE DIREITO DE FRANCA \\ www. revista.direitofranca.br \\ v. 6, n.1, dez/2012, ISSN: 1983-4225}

Keywords: free-will, capacity of culpability, culpability, legal responsibility

\section{INTRODUÇÃO}

Um Estado verdadeiramente democrático de Direito deve garantir a todo cidadão que não haverá crime - e nem punição - sem a prévia averiguação da culpabilidade por parte do autor do delito. Por isso, num Estado democrático de Direito, a culpabilidade é fundamento e limite da própria pena, devendo a sanção imposta ao autor da vontade de ação livre e contrária ao direito ser aplicada proporcionalmente à culpa e à gravidade da ação delituosa.

O fundamento da culpabilidade nos remete à noção de livre-arbítrio - entendido como vontade de ação e liberdade de vontade - tendo em vista que o que se reprova na culpabilidade é sempre um ato (livre) da vontade humana.

A culpabilidade, por sua vez, é o fundamento da responsabilidade jurídica - e, via de consequência, da responsabilização penal - pois o descumprimento e/ou inobservância da conduta prescrita na norma jurídica permite ao Direito, mediante o uso da força aparelhada do Estado, imputar ao autor do ato de vontade uma obrigação.

Contudo, para que o Direito possa aplicar uma sanção (pena) é imperiosa a presença de três requisitos essenciais, quais sejam: capacidade concreta de culpabilidade (imputabilidade), consciência da ilicitude e exigibilidade de conduta diversa. Esses três requisitos essenciais nos remetem diretamente à noção de culpa, de liberdade de vontade e responsabilidade.

O presente estudo tem como objetivo central examinar o fenômeno da culpabilidade, o livre-arbítrio e a responsabilidade jurídico-penal sob a perspectiva do pensamento jusfilosófico de Hans Welzel, precursor da teoria finalista do delito.

Para Welzel, toda atividade/ação humana tem como característica a programação da vontade, isto é, a finalidade proposta pela decisão de vontade da ação. Em outras palavras, Welzel acredita que todo comportamento humano tem como característica uma estrutura finalística, tendo em vista que, em regra, todo comportamento humano é dirigido por uma vontade.

Portanto, para Welzel, o que realmente interessa ao Direito Penal é a finalidade e intencionalidade de uma ação humana, e não a causalidade de fatos e ações. Segundo Welzel, apenas o comportamento humano que pode ser dirigido pela vontade de ação interessa ao Direito 


\section{REVISTA ELETRÔNICA DA \\ FACULDADE DE DIREITO DE FRANCA \\ www.revista.direitofranca.br \\ v. 6, n.1, dez/2012, ISSN: 1983-4225}

Penal. Por isso, o estudo acerca do livre-arbítrio (liberdade de vontade e vontade de ação), fundamento da culpabilidade, é tão relevante na doutrina finalista do delito do mencionado autor.

\section{CULPABILIDADE, VONTADE E LIVRE-ARBÍTRIO}

Segundo Welzel, a culpabilidade é a falta de autodeterminação conforme um fim graças a qual a pessoa pode dirigir sua conduta de acordo com a ordem jurídica da existência a ela confiada - ao realizar uma ação jurídica. ${ }^{1}$

Necessário esclarecer que, para Welzel, a culpabilidade não se remeter à antijuridicidade (relação de discordância entre a ação e a prescrição normativa ${ }^{2}$ ), mas, volta-se à reprovabilidade pessoal da conduta do autor, pois, quando esse poderia ter se eximido de cometer a ação antijurídica. ${ }^{3}$ Afirma Welzel que:

Se a antijuridicidade é o simples juízo de desvalor por não ser a ação como deveria ser de acordo com o Direito - sem levar em conta se o autor podia satisfazer as exigências jurídicas - o juízo de desvalor da culpabilidade vai mais além, e lança sobre o autor a reprovabilidade pessoal por não haver atuado corretamente apesar de ter podido obrar conforme a norma. ${ }^{4}$

Em Welzel, a ideia de culpabilidade está intrinsecamente relacionada à vontade de ação, tendo em vista ser ela o objeto da reprovabilidade e somente por meio dela a ação se concretiza. Assim, "toda culpabilidade é, pois, culpabilidade de vontade." 5 Ora, aquilo que não depende da vontade do homem não pode lhe ser reportado como conduta culpável. ${ }^{6}$

Contudo, há que se ressaltar que, culpabilidade e vontade de agir são conceitos distintos, eis que toda vontade é portadora de culpabilidade - em maior ou menor gradação. A culpabilidade é uma "qualidade valorativa negativa da vontade de ação", e, por isso, no juízo de culpabilidade o que está sob análise é a "reprovabilidade da vontade típica e antijurídica."8

\footnotetext{
2001, p. 87.

${ }^{3}$ WELZEL, Hans. A posição da culpabilidade na estrutura do delito, p. 87.

${ }^{4}$ WELZEL, Hans. A posição da culpabilidade na estrutura do delito, p. 87.

${ }^{5}$ WELZEL, Hans. A posição da culpabilidade na estrutura do delito, p. 88.

${ }^{6}$ WELZEL, Hans. A posição da culpabilidade na estrutura do delito, p. 88.

${ }^{7}$ WELZEL, Hans. A posição da culpabilidade na estrutura do delito, p. 89.

${ }^{8}$ WELZEL, Hans. A posição da culpabilidade na estrutura do delito, p. 89.
}

1 WELZEL, Hans. Culpabilidade e personalidade. In: WELZEL, Hans. O novo sistema jurídico-penal: uma introdução à doutrina da ação finalista. Tradução, prefácio e notas de Luiz Regis Prado. São Paulo: RT, 2001 , p. 105.

${ }^{2}$ WELZEL, Hans. A posição da culpabilidade na estrutura do delito. In: WELZEL, Hans. O novo sistema jurídicopenal: uma introdução à doutrina da ação finalista. Tradução, prefácio e notas de Luiz Regis Prado. São Paulo: RT, 


\section{REVISTA ELETRÔNICA DA FACULDADE DE DIREITO DE FRANCA \\ www.revista.direitofranca.br \\ v. 6, n.1, dez/2012, ISSN: 1983-4225}

Segundo Welzel, para que seja possível analisar a reprovabilidade da culpabilidade de uma conduta, é necessário verificar a resolução de vontade não no sentido abstrato, mas, no sentido concreto, examinando a conduta do indivíduo dentro de uma situação específica, de maneira a se concluir se ele poderia - ou não - ter se conduzido de conformidade com o direito. ${ }^{9}$

Para tanto, ou seja, para analisar-se a reprovabilidade de uma vontade de ação, é necessário, conforme afirma Welzel, que seja verificado o problema do livre-arbítrio. Isto porque, somente a partir do exame do problema do livre-arbítrio podemos apurar se, teoricamente, é possível a adoção de uma resolução de vontade conforme a norma, ao invés de contrária a ela.

Para Welzel, o problema do livre-arbítrio apresenta três aspectos essenciais, quais sejam: o antropológico, o caracteriológico e o categorial.

\subsection{Aspecto antropológico do livre-arbítrio}

Do ponto de vista antropológico, necessário advertir que Welzel desconsidera a teoria evolucionista, de Darwin, porque, para o jurista, não há no homem, durante o processo evolutivo, uma maior especialização dos instintos animais. Para Welzel, o que ocorre é exatamente o contrário, ou seja, há uma verdadeira involução das formas inatas de conduta, tendo em vista que o processo evolutivo do homem caracteriza-se, essencialmente, por atos livres da inteligência. Assim, em seu processo evolutivo, o homem, gradativamente, substitui os seus instintos e impulsos animais (isto é, irracionais) por atos de inteligência (que são geridos pela razão). ${ }^{10}$ Afirma Welzel:

Em contraste fundamental com o animal, o homem caracteriza-se negativamente por uma grande liberdade de formas inatas e instintivas de conduta e positivamente pela capacidade e pela incumbência de descobrir e realizar por si mesmo a conduta correta por meio de atos inteligentes. ${ }^{11}$

Adverte Welzel que, em razão de o pensamento racional ser ordenado categoricamente (ou seja, o homem tem consciência da moral) e, por agir em conformidade com essa

\footnotetext{
${ }^{9}$ WELZEL, Hans. Os pressupostos existenciais da reprovabilidade da culpabilidade: livre arbítrio e imputabilidade. In: WELZEL, Hans. O novo sistema jurídico-penal: uma introdução à doutrina da ação finalista. Tradução, prefácio e notas de Luiz Regis Prado. São Paulo: RT, 2001, p. 93.

${ }^{10}$ WELZEL, Hans. Os pressupostos existenciais da reprovabilidade da culpabilidade, p. 95.

${ }^{11}$ WELZEL, Hans. Os pressupostos existenciais da reprovabilidade da culpabilidade, p. 95.
} 


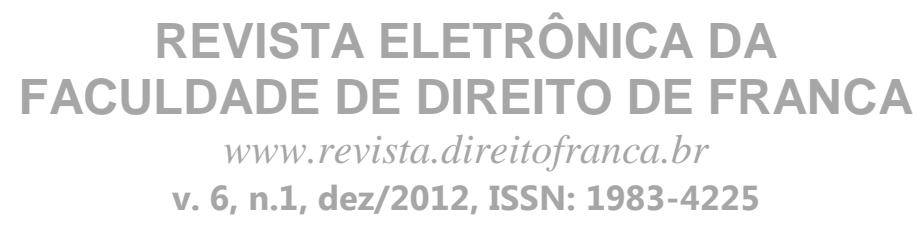

racionalidade, é que o homem revela-se responsável por suas ações, que estão desvinculadas de quaisquer condutas instintivas. ${ }^{12}$

Daí a constatação de Welzel, de que o homem não é um animal pré-destinado, e sim, um animal que constrói o seu próprio destino e traça seu próprio sistema de ação. O homem, por ser livre e consciente de sua disposição à responsabilidade, "tem de elaborar para si [...] seu sistema de ação - no fundo, individual específico - em um período de aprendizagem, preenchendo suas disposições, dadas de um modo geral, mas vazias de toda forma detalhada de execução."13

\subsection{Aspecto caracteriológico do livre-arbítrio}

Segundo Welzel, o retrocesso às formas inatas de conduta e a aparição de um Eu-centro (ou seja, o Eu-consicente, responsável, que dirige nossa vontade de ação conforme uma finalidade e valor $\left.{ }^{14}\right)^{15}$ possibilitou que a estrutura anímica do homem tivesse uma pluralidade de estratos. ${ }^{16}$ Sendo que, essa pluralidade de estratos comporta uma diversidade de impulsos de conservação da espécie e autoconservação, a exemplo das paixões, dos desejos, das ambições, dos interesses, dentre outros.

Contudo, também se verifica que o estrato profundo (que compreende o Eu-semiinconsciente e o Eu-inconsciente ${ }^{17}$ ) é capaz de exercer influência sobre a vontade de ação humana - eis que, não raro, o homem se torna vítima passiva de seus impulsos.

Desse modo, inegável que o homem, embora guiado pela razão, sofre as influências de seu Eu-profundo (semi-inconsciente e inconsciente), e para que os impulsos irracionais sejam

\footnotetext{
${ }^{12}$ WELZEL, Hans. Os pressupostos existenciais da reprovabilidade da culpabilidade, p. 95.

${ }^{13}$ WELZEL, Hans. Os pressupostos existenciais da reprovabilidade da culpabilidade, p. 95.

${ }^{14}$ WELZEL, Hans. Culpabilidade e personalidade, p. 105.

${ }^{15}$ É nesse mesmo sentido que Reale afirma que: "A ação, em seu sentido rigoroso, ou o ato, é energia dirigida para algo, que é sempre um valor. O valor, portanto, é aquilo a que a ação humana tende, porque se reconhece, em um determinado momento, ser motivo, positivo ou negativo da ação mesma. Não se indaga aqui da natureza ou das espécies de valores, mas apenas se verifica que, toda vez que o homem atua, objetiva ou contraria algo de valioso. Atuar sem motivo é próprio do alienado. Alienado à aquele que está alheio ao seu conduzir-se. É o que perdeu o sentido de sua direção e de sua dignidade.” (REALE, Miguel. Filosofia do Direito. 19. ed. São Paulo: Saraiva, 1999, p. 380).

${ }_{16}$ Essa pluralidade de estratos mencionada por Welzel se refere ao Eu-centro (o consciente), ao Eu-profundo (o semi-inconsciente e o inconsciente) e ao Eu-mesmo (o eu da vontade de ação finalística). (Conf.: WELZEL, Hans. Culpabilidade e personalidade. In: WELZEL, Hans. O novo sistema jurídico-penal: uma introdução à doutrina da ação finalista. Tradução, prefácio e notas de Luiz Regis Prado. São Paulo: RT, 2001, p. 105-108.).

${ }^{17}$ WELZEL, Hans. Culpabilidade e personalidade, p. 105-106.
} 


\title{
REVISTA ELETRÔNICA DA FACULDADE DE DIREITO DE FRANCA \\ $w w w . r e v i s t a$. direitofranca.br \\ v. 6, n.1, dez/2012, ISSN: 1983-4225
}

controlados, afirma Welzel, é necessária a elevação do Eu-mesmo, que figura como "centro regulador que nos dirige conforme a finalidade e valor". ${ }^{18}$

Assim, a partir da noção do Eu-mesmo surge um novo modelo de vontade, que não deve ser entendida como simples impulso dirigido à consecução de um fỉm, mas, como ação humana "baseada em um esquema antecipado de seu curso e do resultado." ${ }^{19}$ Nesse sentido, os impulsos e os atos de vontade são dirigidos, precisamente, com base em um conteúdo e finalidade que se estendem para além do momento presente. Em outras palavras, o homem torna-se capaz de controlar os seus impulsos emocionais, como também, o Eu-centro (consciente e racional) é capaz de intervir - e, em geral, direcionar - a decisão da ação, controlando a força emotiva (do Eu-profundo), voltando a sua vontade para a realização de ações com conteúdo de finalidade e com significação valorativa conforme uma configuração correta da vida. Assevera Welzel que, nesse processo, "o impulso valioso é permitido e o conteúdo da força do não valioso destruído."20 E, conclui afirmando que:

\begin{abstract}
Apenas aquilo que nos incita e arrasta um impulso instintivo, uma aspiração, um interesse, pode converter-se em fim de uma decisão da ação, tanto se é adotada de modo instintivo como conforme um fim. A significação insubstituível da função de direção da vontade, orientada finalisticamente, consiste, porém, em que seja possível uma nova configuração da vida humana de acordo com a verdade, na finalidade e no valor, e permite, com isso, ao homem a regulação de seus impulsos, que lhe está confiada de modo responsável após o desaparecimento dos instintos biológicos. ${ }^{21}$
\end{abstract}

\subsection{Aspecto categorial do livre-arbítrio}

$\mathrm{O}$ aspecto categorial do livre-arbítrio, de acordo com Welzel, se remete à necessidade de compreensão do que vem a ser liberdade de vontade, que não deve ser confundida com liberdade de ação. ${ }^{22}$

Segundo Welzel, a importância da compreensão da liberdade de vontade se dá em razão de que, somente a partir dela é possível ao homem o domínio da coação causal por meio de uma direção orientada finalisticamente, em virtude da qual, unicamente, pode o homem ser

\footnotetext{
${ }^{18}$ WELZEL, Hans. Os pressupostos existenciais da reprovabilidade da culpabilidade, p. 96.

${ }^{19}$ LERSCH apud WELZEL, Hans. Os pressupostos existenciais da reprovabilidade da culpabilidade, p. 96.

${ }^{20}$ WELZEL, Hans. Os pressupostos existenciais da reprovabilidade da culpabilidade, p. 97.

${ }^{21}$ WELZEL, Hans. Os pressupostos existenciais da reprovabilidade da culpabilidade, p. 97-98.

${ }^{22}$ WELZEL, Hans. Os pressupostos existenciais da reprovabilidade da culpabilidade, p. 98.
} 


\section{REVISTA ELETRÔNICA DA FACULDADE DE DIREITO DE FRANCA \\ www.revista.direitofranca.br \\ v. 6, n.1, dez/2012, ISSN: 1983-4225}

responsabilizado por ter adotado a decisão errada (contrária à norma) em lugar da correta (conforme a norma). ${ }^{23}$

Welzel define a liberdade de vontade como "capacidade de poder reger-se conforme os fins". ${ }^{24}$ Para ele, a liberdade de vontade não é um estado, mas um ato: ato de liberdade da coação causal (cega, indiferente e inconsequente) para a autodeterminação conforme os fins. ${ }^{25}$ Nesse entendimento, Welzel assevera que:

El acto de conocimiento es libre (y tiene que ser libre) de determinantes causales ('ciegas'), para que sea posible uma determinación conforme al sentido, de acuerdo com el objeto de conocimiento. Sólo si se destaca esta forma (especifica) de determinación y se la distingue claramente de la determinación causal, se puede comprender su peculiaridad y com ella la libertad para la autodeterminación conforme al sentido. Em cambio, la inclusión indiscriminada de la determinación conforme al sentido en la determinación causal impide precisamente la comprensión de la autodeterminación conforme al sentido. ${ }^{26}$

Portanto, pode-se constatar que, para Welzel, a liberdade de vontade é pressuposto para a decisão e realização de condutas conforme à razão - ou seja, em conformidade com os fins e valores do justo; e nada tem a ver com a possibilidade de poder de escolha cega entre o correto e o incorreto, o valor e o desvalor. Por isso, a liberdade de vontade se refere à ação livre de impulsos emotivo-irracionais, voltada para a autodeterminação conforme os fins. ${ }^{27}$

Nesse entendimento, Welzel conclui que é na ausência da liberdade de vontade (ou seja, é na vontade dissociada da razão) que se fundamenta o fenômeno da culpabilidade, que pode ser compreendida como "falta de autodeterminação conforme os fins num sujeito que era capaz de determinar-se." ${ }^{28}$ E, prossegue Welzel, afirmando que:

\footnotetext{
${ }^{23}$ WELZEL, Hans. Os pressupostos existenciais da reprovabilidade da culpabilidade, p. 98-99.

${ }^{24}$ WELZEL, Hans. Os pressupostos existenciais da reprovabilidade da culpabilidade, p. 100.

${ }^{25}$ WELZEL, Hans. Os pressupostos existenciais da reprovabilidade da culpabilidade, p. 100.

${ }^{26}$ WELZEL, Hans. Reflexiones sobre el "libre albedrio". In: WELZEL, Hans. Estudios de filosofia del derecho y derecho penal. Trad. de Gustavo Eduardo Aboso y Tea Löw. Buenos Aires: B de F, Julio César Faira, 2004, p. 38. peculiaridade e com ela a liberdade para a autodeterminação conforme o sentido. Por outro lado, a inclusão indiscriminada da determinação conforme ao sentido na determinação causal impede precisamente a compreensão da autodeterminação conforme o sentido." - Tradução minha).

${ }^{27}$ WELZEL, Hans. Os pressupostos existenciais da reprovabilidade da culpabilidade, p. 101.

${ }^{28}$ WELZEL, Hans. Os pressupostos existenciais da reprovabilidade da culpabilidade, p. 101.
} ("O ato de conhecimento é livre (e tem que ser livre) de determinantes causais ('cegas'), para que seja possível uma determinação conforme ao sentido, de acordo com o objeto de conhecimento. Somente quando se destaca esta forma (específica) de determinação e se a distingue claramente da determinação causal, se pode compreender sua 


\title{
REVISTA ELETRÔNICA DA FACULDADE DE DIREITO DE FRANCA \\ www.revista.direitofranca.br \\ v. 6, n.1, dez/2012, ISSN: 1983-4225
}

\begin{abstract}
A culpabilidade não significa 'livre' decisão em favor do mal, mas ficar preso pela coação causal aos impulsos, sendo o sujeito capaz de autodeterminação conforme os fins. O delito é, por isso, efetivamente, inteiramente, um produto de fatores causais e, a suposição e inclusive a indicação da porcentagem com que a 'vontade livre do autor' tenha participado, junto à disposição e ao mundo circundante, da gênese do delito é um jogo incerto. O Direito Penal [...] parte do conhecimento antropológico de que o homem, como ser determinado à responsabilidade, está existencialmente em condições de conduzir (conforme os fins) a dependência causal dos impulsos. A culpabilidade não é um ato de livre autodeterminação, mas precisamente a falta de uma decisão conforme a finalidade em um sujeito responsável. ${ }^{29}$
\end{abstract}

Ainda, acerca do aspecto categorial do livre-arbítrio, vale acrescentar que, Welzel vê, com ressalvas, o determinismo tradicional (que leva em consideração somente uma forma de determinação, conhecida como monismo causal, adotada por Adolf Merkel e Karl Engisch, que partiam da admissão hipotética do determinismo para explicar a responsabilidade penal ${ }^{30}$ ). De outro modo, acredita que o indeterminismo tradicional, quando anula o sujeito responsável, deve ser desconsiderado. ${ }^{31}$ Assim, para Welzel, o determinismo não pode ser descartado, mas, é necessário haver uma melhor compreensão do mesmo.

Para explicar como se processa a liberdade de ação e vontade no ser humano, Welzel parte do argumento de conhecimento $^{32}$ - formulado contra a utilização unilateral do determinismo causal no chamado problema do livre arbítrio.

Segundo Welzel, todo ato - conduta - é precedida por um momento de pensamento - ou ainda, por um momento de conhecimento. E todo ato de conhecimento se volta para um objeto de conhecimento, motivo pelo qual "o conhecimento não depende somente da vontade daquele que pensa, mas, também, e na mesma medida, do objeto em que se pensa ${ }^{33}$, pois “os atos de conhecimento estão tão determinados pelo objeto de conhecimento como estão os sujeitos cognocentes." 34

Contudo, a relação entre o sujeito cognocente e o objeto cognoscível, no que se refere aos atos de liberdade, não é equivalente a relação de causalidade das ciências naturais e, por isso,

\footnotetext{
36.

${ }^{31}$ WELZEL, Hans. Reflexiones sobre el "libre albedrio", p. 32 e 39-40.

${ }^{32}$ WELZEL, Hans. Reflexiones sobre el "libre albedrio", p. 39-40.

${ }^{33}$ WELZEL, Hans. Reflexiones sobre el "libre albedrio", p. 35.

${ }^{34}$ WELZEL, Hans. Reflexiones sobre el "libre albedrio", p. 35.
}

${ }^{29}$ WELZEL, Hans. Os pressupostos existenciais da reprovabilidade da culpabilidade, p. 101-102.

${ }^{30}$ WELZEL, Hans. Reflexiones sobre el "libre albedrio". In: WELZEL, Hans. Estudios de filosofia del derecho y derecho penal. Trad. de Gustavo Eduardo Aboso y Tea Löw. Buenos Aires: B de F, Julio César Faira, 2004, p. 31- 


\section{REVISTA ELETRÔNICA DA FACULDADE DE DIREITO DE FRANCA \\ www.revista.direitofranca.br \\ v. 6, n.1, dez/2012, ISSN: 1983-4225}

não pode haver uma interpretação meramente determinista da vida anímica, pois no âmbito das ciências sociais aplicadas, as ações humanas devem ser analisadas segundo conteúdos de sentido, e as condutas com relevância jurídica devem ser analisadas e julgadas de acordo com preceitos legais, regras da lógica formal e da doutrina do método jurídico. ${ }^{35}$ Desse modo, para Welzel, todo ato de conhecimento é, por si só, livre, isto é, livre de determinantes causais, e deve ser livre "para que seja possível uma determinação conforme o sentido, de acordo com o objeto de conhecimento." ${ }^{36}$ A liberdade de conhecimento faz com que seja possível, também, a autodeterminação conforme o sentido, sendo que "o conhecimento e o impulso de conhecer têm que ser compreendidos como uma tarefa plena de sentido, que possa ser sustentada frente aos impulsos contrapostos. ${ }^{37}$

Destarte, consoante preconiza Welzel, a conduta humana se desenvolve não somente no mundo da força e da intensidade dos impulsos, mas também, num mundo pleno de significações, no qual os motivos compreendem critérios de sentido, segundo os quais o homem como ser espiritual possui um lugar e uma tarefa para ser cumprida e realizada. ${ }^{38}$

Conclui-se, aqui, que em Welzel, a ideia de livre-arbítrio coincide com a concepção moderna de liberdade e autonomia (como entendida, por exemplo, por Kant e Hegel), em que o livre-arbítrio não dever ser confundido com livre escolha - aleatória e arbitrária - entre o fazer o bem ou o mal (ou ainda, entre conduzir-se de maneira correta ou incorreta), mas sim, compreendido como autodeterminação conforme a razão, por haver a total consciência da responsabilidade por suas decisões de vontade.

\section{LIVRE-ARBÍTRIO, IMPUTABILIDADE E RESPONSABILIDADE JURÍDICA}

Após o exame do problema do livre-arbítrio, que intenta apresentar uma resposta no que se refere à possibilidade, teórica, de se adotar uma resolução de vontade correta, ao invés de uma equivocada, resta examinar o problema da imputabilidade - ou seja, da capacidade concreta de culpabilidade.

\footnotetext{
${ }^{35}$ WELZEL, Hans. Reflexiones sobre el "libre albedrio", p. 35-36.

${ }^{36}$ WELZEL, Hans. Reflexiones sobre el "libre albedrio", p. 38.

${ }^{37}$ WELZEL, Hans. Reflexiones sobre el "libre albedrio", p. 42.

${ }^{38}$ WELZEL, Hans. Reflexiones sobre el "libre albedrio", p. 42-43.
} 


\section{REVISTA ELETRÔNICA DA FACULDADE DE DIREITO DE FRANCA \\ www.revista.direitofranca.br \\ v. 6, n.1, dez/2012, ISSN: 1983-4225}

Conforme acima mencionado, a ausência da liberdade de vontade dá ensejo ao fenômeno da culpabilidade. Assim, para que se possa encontrar uma solução para o problema da imputabilidade, afirma Welzel, é necessário considerar a culpabilidade em seu aspecto concreto isto é, averiguando-se a situação fática de modo empírico-prático. ${ }^{39}$

Contudo, segundo Welzel, a capacidade concreta de culpabilidade de um homem não é, a princípio, passível de objetivação (análise empírica), eis que não é possível conhecer a subjetividade do sujeito da ação ${ }^{40}$, sob pena de se aniquilar a sua própria essência. ${ }^{41}$ Diante disso, Welzel esclarece que:

Aquele ato pelo qual o homem se eleva para além do mundo dos objetos, da experiência, para converter-se em um sujeito responsável, não pode ser nunca objetivado. É o solutamente não-objetivo que não pode ser convertido jamais em objeto sem ser destruído em sua essência. O juízo de que um homem determinado, em uma determinada situação, é capaz de culpabilidade, não é, portanto, um ato teórico, mas um ato puramente existencial e de caráter 'comunicativo': é o reconhecimento do outro como a si mesmo, como um igual, como suscetível de determinação plena de sentido e por isso tão sujeito responsável como aquele que o julga. ${ }^{42}$

Por isso, o juízo de culpabilidade, em Welzel, deve ser formulado de modo negativo, ou seja, excluindo-se todos aqueles homens que não são (ou, que ainda não são) capazes de conduzir suas ações de vontade com autodeterminação plena de sentido (como é o caso, por exemplo, dos débeis mentais, ou das crianças).

Desse modo, todos os homens capazes de autodeterminar-se conforme os fins (entendendo-se fim como dever ser do valor reconhecido racionalmente como motivo de agir) são, igualmente, capazes de culpabilidade.

Em Welzel, a capacidade concreta de culpabilidade dever ser entendida, pois, como imputabilidade, ${ }^{43}$ que significa a capacidade de um homem "compreender o injusto do fato e de decidir-se de acordo com essa compreensão."44 Portanto, de acordo com Welzel, a imputabilidade (ou, capacidade concreta de culpabilidade) significa atribuir uma responsabilidade a alguém pela autodeterminação de uma vontade livre.

\footnotetext{
${ }^{39}$ WELZEL, Hans. Os pressupostos existenciais da reprovabilidade da culpabilidade, p. 102.

${ }^{40}$ WELZEL, Hans. Os pressupostos existenciais da reprovabilidade da culpabilidade, p. 103.

${ }^{41}$ WELZEL, Hans. Os pressupostos existenciais da reprovabilidade da culpabilidade, p. 103.

${ }^{42}$ WELZEL, Hans. Os pressupostos existenciais da reprovabilidade da culpabilidade, p. 103.

${ }^{43}$ WELZEL, Hans. Os pressupostos existenciais da reprovabilidade da culpabilidade, p. 103.

${ }^{44}$ WELZEL, Hans. Os pressupostos existenciais da reprovabilidade da culpabilidade, p. 103.
} 


\section{REVISTA ELETRÔNICA DA \\ FACULDADE DE DIREITO DE FRANCA \\ www.revista.direitofranca.br \\ v. 6, n.1, dez/2012, ISSN: 1983-4225}

Importa ressaltar que, a culpabilidade jurídica não coincide com a culpabilidade moral, pois, aquela é mais extensa e vai além desta. Welzel assevera que:

A reprovabilidade da resolução de vontade deve alcançar certa medida, socialmente relavante, antes que se converta em culpabilidade jurídica, em culpabilidade ante a comunidade jurídica. Deve ter sido infringida, pelo menos, aquela medida de respeito aos deveres sociais, que possa e deva observar, em princípio, qualquer outro membro da comunidade jurídica no lugar do autor. Quando o prórpio juiz não poderia atuar, corretamente, de outro modo, que não o modo como atuou o autor, falta a culpabilidade jurídica como reprovabilidade social do fato. ${ }^{45}$

Assim é que, para Welzel, quando há a constatação da concorrência dos elementos intelectuais e volitivos da culpabilidade, "o fato antijurídico é reprovável e em princípio punível" ${ }^{46}$ Ademais, a culpabilidade jurídica enseja, a princípio, a punição (aplicação de uma sanção), tendo em vista que a teoria da culpabilidade fundamenta-se no princípio da responsabilidade, "segundo o qual o homem é responsável pela antijuridicidade de suas decisões, dentro dos limites de sua capacidade de conhecimento ético-social". ${ }^{47}$

No que diz respeito ao princípio da responsabilidade, Welzel esclarece que:

O princípio da responsabilidade torna, por um lado, responsável o sujeito pelo fato de o conteúdo de suas resoluções de vontade não estar conforme o ordenamento jurídico (sempre que o autor, de acordo com a medida de sua capacidade de conhecimento éticosocial, puder conhecer a antijuridicidade de sua conduta) e, por outro lado, limita sua responsabilidade pela realização, de acordo com o cuidado devido, de suas decisões juridicamente irrelevantes, ao perigo para bens jurídicos especialmente importantes. Com isso, a teoria da culpabilidade fixa claramente, de modo positivo e negativo, os limites da responsabilidade ético-social da pessoa. ${ }^{48}$

De outro modo, a punição - sanção jurídica atribuída ao autor de uma conduta típica, antijurídica e culpável - é uma resposta ao descumprimento de um dever jurídico (entendendo-se dever jurídico como a "relação que se trava entre uma pessoa e uma norma jurídica"49). Dito de outra maneira, "o descumprimento de um dever faz com que se impute à pessoa que o viola uma responsabilidade". ${ }^{50}$ A responsabilidade jurídica - e a consequente aplicação de uma punição

\footnotetext{
${ }^{45}$ WELZEL, Hans. Os elementos da reprovabilidade, p. 141.

${ }^{46}$ WELZEL, Hans. Os elementos da reprovabilidade, p. 143.

${ }^{47}$ WELZEL, Hans. Os elementos da reprovabilidade, p. 118.

${ }^{48}$ WELZEL, Hans. Os elementos da reprovabilidade, p. 121-122.

${ }^{49}$ CAVALCANTI, Arthur José Faveret. A estrutura lógica do direito. Rio de Janeiro: Renovar, 1996, p. 105.

${ }^{50}$ CAVALCANTI, Arthur José Faveret. A estrutura lógica do direito, p. 64.
} 


\section{REVISTA ELETRÔNICA DA \\ FACULDADE DE DIREITO DE FRANCA \\ www. revista.direitofranca.br \\ v. 6, n.1, dez/2012, ISSN: 1983-4225}

(sanção) - se dá, pois, em razão de o autor do ato de vontade (livre) ter infringido uma norma que lhe vedava a realização de uma determinada conduta.

\section{IUS PUNIENDI E A NECESSÁRIA PROTEÇÃO AOS VALORES ÉTICO-SOCIAIS}

Como já demonstrado anteriormente, a noção de culpa tem como fundamento a vontade de ação (desde que seja livre), a conduta contrária ao direito e a capacidade de compreensão do indivíduo acerca do caráter injusto de seus atos. Destarte, a capacidade concreta de culpabilidade se remete à imputabilidade - ou seja, a atribuição a alguém quanto à responsabilidade de alguma coisa (fato ou ato).

A responsabilidade jurídica, vista sob a perspectiva do Direito Penal, é a obrigação que uma pessoa tem de arcar com as consequências jurídicas do delito, tendo em vista a necessidade de prestar contas de seu ato e, para tanto, o sujeito da ação deve ser imputável. Vale ressaltar, ainda, que toda obrigação é expressão de um dever, devendo sempre envolver um vínculo. ${ }^{51}$ Desse modo, a obrigação sempre envolverá um vínculo (culpa) e o fator prestação (responsabilidade). ${ }^{52}$ Por isso, o dever "refere-se à conduta do sujeito que, por seu comportamento, pode provocar ou evitar a sanção; a responsabilidade refere-se ao objeto da sanção, isto é, a quem suporta a sanção." 53

Para Welzel, a principal tarefa do Direito é superar (ou ainda, conter) a guerra civil (luta de todos contra todos), instaurando e mantendo a ordem social, de modo a assegurar a vida e a boa convivência social. ${ }^{54}$ Por isso, em Welzel, há uma estreita relação entre a proteção aos bens jurídicos e a obediência $^{55}$, eis que o Direito, por meio da força aparelhada do Estado (coerção legítima $^{56}$ ), deve garantir a segurança de todos perante todos, estabelecendo normas,

\footnotetext{
${ }^{51}$ FERRAZ JÚNIOR, Tércio Sampaio. Introdução ao estudo do Direito: técnica, decisão, dominação. 4. ed. São Paulo: Atlas, 2003, p. 162.

${ }^{52}$ FERRAZ JÚNIOR, Tércio Sampaio. Introdução ao estudo do Direito: técnica, decisão, dominação, p. 162.

${ }^{53}$ FERRAZ JÚNIOR, Tércio Sampaio. Introdução ao estudo do Direito: técnica, decisão, dominação, p. 161.

${ }^{54}$ WELZEL, Hans. Derecho natural y positivismo jurídico. In: WELZEL, Hans. Estudios de filosofia del derecho y derecho penal. Trad. de Gustavo Eduardo Aboso y Tea Löw. Buenos Aires: B de F, Julio César Faira, 2004, p. 192.

${ }^{55}$ WELZEL, Hans. Derecho natural y positivismo jurídico, p. 192.

${ }^{56}$ WELZEL, Hans. El problema de la validez del Derecho: uma cuestión limite del derecho. In: RADBRUCH, G., SCHIMIDT, E., WELZEL, H. Derecho injusto y derecho nulo. Madrid: Aguilar, 1971, p. 87-88.
} 


\section{REVISTA ELETRÔNICA DA FACULDADE DE DIREITO DE FRANCA \\ www.revista.direitofranca.br \\ v. 6, n.1, dez/2012, ISSN: 1983-4225}

reconhecidas pela sociedade em geral como obrigatórias ${ }^{57}$, que protejam os valores ético-sociais mais relevantes para a sociedade. ${ }^{58}$

O "direito de punir" do Estado, segundo Welzel, é legitimado, precisamente, quando há o descumprimento do dever jurídico-penal, pois cabe ao Direito livrar a sociedade do caos, proporcionando uma convivência digna e segura para toda a comunidade. ${ }^{59}$ Contudo, Welzel nos adverte que, o Direito Penal deve limitar-se a atuar nos casos em que houver graves ataques contra os valores ético-sociais mais caros à sociedade. Portanto, não são quaisquer valores que estão sujeitos à proteção do Direito Penal, mas tão-somente, segundo Welzel, aqueles valores fundamentais e essenciais à vida social. ${ }^{60}$

Pode-se concluir, a partir do pensamento de Welzel, que, na prática, as penas previstas nas normas jurídico-penais são efetivamente aplicadas a uma minoria da população, tendo em vista que, quando o sistema jurídico é legítimo e dotado de eficácia, a grande maioria da população reconhece a obrigatoriedade das condutas prescritas nas normas jurídico-penais ${ }^{61}$, uma vez que seu conteúdo reflete, em última instância, os anseios e valores morais mais importantes para a sociedade. ${ }^{62}$ Desse modo, percebe-se que, em Welzel, a construção de todo ordenamento jurídico justo - incluindo-se o sistema jurídico-penal - fundamenta-se, finalisticamente, na proteção dos valores ético-sociais mais caros à sociedade, eis que tal proteção é necessária para que se assegure o exercício da liberdade e autonomia de seus membros, revelando a estreita relação entre o direito e a moral em seu pensamento jusfilosófico.

Portanto, para Welzel, a função essencial do Direito Penal não é a proteção aos bens jurídicos (em especial, os bens materiais). A função essencial do Direito Penal é, precisamente, assegurar e proteger os valores ético-sociais sob uma ótica positiva (ou seja, por meio de um direito positivo, real e factível ${ }^{63}$ ), instituindo-se regras e normas de conduta que determinem e expressem o reconhecimento de valores dignos de proteção. Assim sendo, entende Welzel que, a punição é aplicada como forma de o Estado demonstrar que os valores ético-sociais infringidos

\footnotetext{
${ }^{57}$ WELZEL, Hans. El problema de la validez del Derecho: uma cuestión limite del derecho, p. 88.

${ }^{58}$ WELZEL, Hans. El problema de la validez del Derecho: uma cuestión limite del derecho, p. 111-112.

${ }^{59}$ WELZEL, Hans. El problema de la validez del Derecho: uma cuestión limite del derecho, p. 193.

${ }^{60}$ WELZEL, Hans. Derecho penal alemán. Trad. Juan Bustos Ramirez e Sérgio Yáñez Perez. Santiago: Ed. Jurídica do Chile, 1970, p. 11.

${ }^{61}$ WELZEL, Hans. El problema de la validez del Derecho: uma cuestión limite del derecho, p. 82-84.

${ }^{62}$ WELZEL, Hans. Derecho penal alemán, p. 11-12.

${ }^{63}$ WELZEL, Hans. Derecho natural y positivismo jurídico, p. 192.
} 


\section{REVISTA ELETRÔNICA DA FACULDADE DE DIREITO DE FRANCA \\ www.revista.direitofranca.br \\ v. 6, n.1, dez/2012, ISSN: 1983-4225}

continuam sendo valorados e reafirmados como importantes para toda a sociedade. Dito de outra maneira: quando se aplica uma pena, o Estado está reafirmando a importância de se garantir e preservar os valores ético-sociais relevantes para uma determinada sociedade, demonstrando, ainda, que a liberdade de vontade humana deve estar voltada para ações conforme ao direito, e não contrárias a ele.

Ademais, há que se destacar que, para Welzel, os valores ético-sociais que merecem especial proteção por parte do direito não são absolutos e possuem universalidade relativa, uma vez que variam de acordo com o tempo e as condicionantes históricas, o espaço geográfico e a experiência (e vivência) específica de cada sociedade. Nesse sentido, merecem destaque as palavras de Welzel:

Las reglas universales del Derecho possen em general, una universalidad relativa, empírica y, en ningún caso, una validez universal absoluta supratemporal. Por eso, su contenido no puede tener la evidencia obligatoria de conceptos essenciales atemporales sino que depende fundamentalmente de condiciones temporales y empíricas que pueden sólo obtenerse em la experiência. ${ }^{64}$

Ainda, vale esclarecer que, para Welzel, o direito somente será reconhecido pela população em geral, se estiver assentado no ideal de justiça, pois, para ele, o que não é direito continua sem ser direito ainda que, na prática, seja emanado e imposto pelo Estado. ${ }^{65}$

Por fim, importa salientar que, segundo Welzel, existe um único princípio material imanente que nenhuma disposição estatal - ou ainda, que nenhum sistema jurídico - pode violar, sob pena de perder toda a sua legitimidade e força obrigatória: este princípio/ valor é a autonomia ética do próximo. ${ }^{66}$ Leciona Welzel que:

Sólo un valor puede obligarnos y en este caso, nos obliga éticamente. Hay también deberes juridicos, pero sólo como deberes éticos. Porque la vida, como decia Aristoteles, es un bien, un orden que nos assegura la vida, nos obliga éticamente. Pero su fuerza obligatoria termina alli donde ordena ir contra un bien que éticamente no puede ser afectado bajo ninguma circunstancia. Y este bien ES la autonomia ética del prójimo. Como la persona, gracias a su autonomia ética, posee un valor próprio

\footnotetext{
${ }^{64}$ WELZEL, Hans. Derecho natural y positivismo jurídico, p. 191. (“As regras universais de Direito possuem, em geral, uma universalidade relativa, empírica e, em nenhum caso, uma validez universal absoluta supratemporal. Por isso, seu conteúdo não pode ter a evidência obrigatória de conceitos essenciais atemporais, senão que depende fundamentalmente de condições temporais e empíricas que podem ser obtidas na experiência." - Tradução livre.).

${ }^{65}$ WELZEL, Hans. El problema de la validez del Derecho: uma cuestión limite del derecho, p. 73-74.

${ }^{66}$ WELZEL, Hans. Derecho natural y positivismo jurídico, p. 198.
} 


\section{REVISTA ELETRÔNICA DA FACULDADE DE DIREITO DE FRANCA \\ www.revista.direitofranca.br \\ v. 6, n.1, dez/2012, ISSN: 1983-4225}

independiente de toda outra persecusión de fines, tiene que ser respetada en su próprio valor por todos los demás. ${ }^{67}$

Para Welzel, o direito justo e legítimo (entenda-se: o direito dotado de positividade, validade formal, validade social e validade axiológica ${ }^{68}$ ) jamais poderá considerar o homem como "coisa" (isto é, como meio para qualquer fim), como também, nunca deverá instituir regras de conduta ou punições que violem a dignidade da pessoa humana. ${ }^{69}$

\section{CONSIDERAÇÕES FINAIS}

Diante do exposto, verifica-se que, para Welzel, toda ação humana, em regra, possui finalidade que se encerra no momento da tomada da decisão de vontade da ação. Por isso, todo comportamento humano livre e consciente tem uma estrutura finalística, eis que dirigido por uma vontade. Assim sendo, para Welzel, o objeto de interesse do Direito Penal é, justamente, a finalidade e intencionalidade de uma ação humana.

Considerando-se, pois, que segundo Welzel, o principal ponto de interesse da dogmática jurídico-penal é o comportamento humano que pode ser dirigido pela vontade de ação, o exame acerca do problema do livre-arbítrio é necessário, tendo em vista ser ele o ponto de partida e o fundamento da culpabilidade - e, via de consequência, da imputabilidade e da responsabilidade jurídica.

A culpabilidade está intrinsecamente ligada à ideia da liberdade de vontade e à vontade de ação, de maneira que o que não depende da vontade do homem não pode lhe ser reportado como conduta culpável, e por isso, não merece maior exame do Direito Penal.

No que se refere ao livre-arbítrio, Welzel demonstra que, em razão de o homem ser racional e por ter seu comportamento ordenado categoricamente (uma vez que possui consciência

\footnotetext{
${ }^{67}$ WELZEL, Hans. Derecho natural y positivismo jurídico, p. 198. ("Somente um valor pode nos obrigar e neste caso, nos obriga eticamente. Há também deveres jurídicos, e outros que são somente deveres éticos. Porque a vida, como dizia Aristóteles, é um bem, uma ordem que nos assegura a vida, nos obrigando eticamente. Contudo, sua força obrigatória termina ali onde ordena ir contra um bem que eticamente não pode ser afetado sob nenhuma circunstância. E este bem é a autonomia ética do próximo. A pessoa, graças a sua autonomia ética, possui um valor próprio independente de toda outra perseguição de fins, e tem que ser respeitada em seu próprio valor por todos os demais. - Tradução livre.).

${ }^{68}$ WELZEL, Hans. El problema de la validez del Derecho: uma cuestión limite del derecho, p. 84 e ss.

${ }^{69}$ WELZEL, Hans. El problema de la validez del Derecho: uma cuestión limite del derecho, p. 198-199.
} 


\section{REVISTA ELETRÔNICA DA FACULDADE DE DIREITO DE FRANCA \\ $w w w . r e v i s t a$. direitofranca.br \\ v. 6, n.1, dez/2012, ISSN: 1983-4225}

dos valores morais da sociedade em que vive) deve, a princípio, agir em conformidade com essa racionalidade, revelando a sua disposição à responsabilidade.

Welzel reconhece que o homem não é somente um ser inteligível, mas, também, um ser sensível. Assim, apesar de dotado de racionalidade, o homem não deixa de, por vezes, agir por impulsos - revelando atitudes irracionais, contrárias à razão. Contudo, todo homem deve ser capaz de controlar os seus impulsos e instintos irracionais-emotivos, de modo a poder conviver, pacificamente, em sociedade.

Segundo Welzel, apesar de o Eu-semi-inconsciente e o Eu-inconsciente exercerem influência sobre a vontade de ação humana, tornando o homem uma vítima passiva de seus impulsos, o Eu-centro (consciente e racional) deve ser capaz de intervir e direcionar a decisão da ação, controlando a força emotiva (do Eu-profundo), possibilitando ao homem realizar ações com conteúdo de finalidade e com significação valorativa conforme uma configuração correta da vida.

A ausência da liberdade de vontade (ou seja, a vontade dissociada da razão) dá ensejo ao fenômeno da culpabilidade, uma vez que impede o homem de autodeterminar-se conforme os fins. Dito de outro modo, o mau uso do livre-arbítrio dá ensejo à culpabilidade e à responsabilidade jurídica, e via de consequência, à punição. E, a punição (aplicação da pena) é essencial para que os valores ético-sociais mais relevantes sejam reafirmados e reforçados perante os membros de determinada sociedade.

Desse modo, restou claro que, em Welzel, a principal tarefa do Direito é coordenar e assegurar que todos os membros da sociedade possam usufruir de sua liberdade de vontade (autonomia), desde que a fruição dessa liberdade não afete a liberdade dos outros. Em outras palavras, em Welzel, o Direito é necessário para a manutenção da ordem social.

Pode-se inferir, ainda, que o "direito de punir" do Estado é legitimado, precisamente, quando há, de algum modo, o desrespeito à ordem social ou aos seus valores ético-sociais mais relevantes. Por isso, para Welzel, cabe ao Direito proporcionar uma convivência digna e segura para toda a comunidade, sendo que, as sanções punitivas devem ser efetivamente aplicadas somente quando houver graves ataques contra os valores ético-sociais mais caros à sociedade.

Para Welzel, a função essencial do Direito Penal é, precisamente, proteger os valores ético-sociais sob uma ótica positiva, instituindo normas jurídicas que expressem o reconhecimento de valores dignos de proteção. 


\section{REVISTA ELETRÔNICA DA \\ FACULDADE DE DIREITO DE FRANCA \\ www.revista.direitofranca.br \\ v. 6, n.1, dez/2012, ISSN: 1983-4225}

Para Welzel, o direito justo e legítimo tem como obrigação punir todo aquele indivíduo que, por seu ato de vontade (livre e consciente), viole a dignidade da pessoa humana.

\section{REFERÊNCIAS BIBLIOGRÁFICAS:}

CAVALCANTI, Arthur José Faveret. A estrutura lógica do direito. Rio de Janeiro: Renovar, 1996.

FERRAZ JÚNIOR, Tércio Sampaio. Introdução ao estudo do Direito: técnica, decisão, dominação. 4. ed. São Paulo: Atlas, 2003.

REALE, Miguel. Filosofia do Direito. 19. ed. São Paulo: Saraiva, 1999.

WELZEL, Hans. El problema de la validez del Derecho: uma cuestión limite del derecho. In: RADBRUCH, G., SCHIMIDT, E., WELZEL, H. Derecho injusto y derecho nulo. Madrid: Aguilar, 1971, p. 73-127.

. Reflexiones sobre el "libre albedrio". In: WELZEL, Hans. Estudios de filosofia del derecho y derecho penal. Trad. de Gustavo Eduardo Aboso y Tea Löw. Buenos Aires: B de F, Julio César Faira, 2004, p. 31-45.

Derecho natural y positivismo jurídico. In: WELZEL, Hans. Estudios de filosofia del derecho y derecho penal. Trad. de Gustavo Eduardo Aboso y Tea Löw. Buenos Aires: B de F, Julio César Faira, 2004, p. 177-199.

Derecho penal alemán. Trad. Juan Bustos Ramirez e Sérgio Yáñez Perez. Santiago: Ed. Jurídica do Chile, 1970.

. A posição da culpabilidade na estrutura do delito. In: WELZEL, Hans. O novo sistema jurídico-penal: uma introdução à doutrina da ação finalista. Tradução, prefácio e notas de Luiz Regis Prado. São Paulo: RT, 2001, p. 87-92.

- Os pressupostos existenciais da reprovabilidade da culpabilidade: livre arbítrio e imputabilidade. In: WELZEL, Hans. O novo sistema jurídico-penal: uma introdução à doutrina da ação finalista. Tradução, prefácio e notas de Luiz Regis Prado. São Paulo: RT, 2001, p. 93104. 


\section{REVISTA ELETRÔNICA DA \\ FACULDADE DE DIREITO DE FRANCA \\ www.revista.direitofranca.br \\ v. 6, n.1, dez/2012, ISSN: 1983-4225}

Culpabilidade e personalidade. In: WELZEL, Hans. O novo sistema jurídico-penal: uma introdução à doutrina da ação finalista. Tradução, prefácio e notas de Luiz Regis Prado. São Paulo: RT, 2001, p. 105-108.

Os elementos da reprovabilidade. In: WELZEL, Hans. O novo sistema jurídico-penal: uma introdução à doutrina da ação finalista. Tradução, prefácio e notas de Luiz Regis Prado. São Paulo: RT, 2001, p. 109-144. 